\section{El participante sensible: extendiendo la metodolo- gía de la validez de contenido}

\section{The sensitive patient: extending the methodology of content validity}

\section{Señor Editor.}

Las consideraciones éticas son indispensables para diseñar y conducir una investigación científica, y deben ser consideradas durante el diseño de la investigación. Por lo mismo, es muy necesaria la existencia de un comité de asuntos éticos que verifique y emita un juicio independiente del autor. Sin embargo, ¿es posible involucrar al participante del estudio en alguna parte de este proceso? En un enfoque que conceptualiza al sujeto de investigación como participante de la investigación, hay nuevos desafíos para afrontar ${ }^{1}$, y estos deben ser trasladados en prácticas que faciliten un rol más activo del participante. Esto usualmente es cristalizado en los investigadores con base en la comunidad ${ }^{2,3}$, en que el conocimiento tácito y explícito de los participantes de la investigación son elegidos como fuente esencial de información, bajo la premisa de su singularidad y su diferencia experiencial con el investigador ${ }^{3}$.

Esta carta pone en relieve el potencial involucramiento del participante del estudio, como una fuente para evaluar las implicancias éticas durante la recolección de datos. Básicamente, el participante puede emitir un juicio sobre el impacto del contenido de los ítems de un cuestionario o método de auto-informe, el cual es predominante en ciencias conductuales ${ }^{4}$; éste mismo procedimiento se usa en la validez de contenido, en que jueces expertos reportan su juicio sobre la claridad y relevancia de los ítems $s^{5}$. Sin embargo, los juicios también pueden ser emitidos por los participantes de investigación, debido a su experiencia y conocimientos tácitos o explícitos ${ }^{3}$ y porque existen discrepancias cuando se los comparan con jueces expertos ${ }^{6}$. En este razonamiento, los participantes también pueden emitir su juicio sobre el contenido de los ítems, y corroborar si tal contenido produciría reacciones no intencionadas como incomodidad, malestar, estrés, o ansiedad. Estas son reacciones emocionales que pueden producir una varianza irrelevante en la interpretación de los resultados. Más crítico aún puede ser el malestar emocional reactivo en el participante, que puede ser más importante y el bien superior para proteger. Por lo tanto, junto con evaluar la claridad y la relevancia de un contenido, como habitualmente se hace en la validez de contenido mediante jueces o participantes ${ }^{5}$, también se puede explorar el grado de impacto negativo que se produciría al leer el contenido del ítem durante la aplicación del cuestionario. El impacto negativo se refiere las reacciones de incomodidad y/o emocionales vinculadas a la lectura del contenido del cuestionario. Si esta reactividad no es el objetivo de un cuestionario, entonces es amenaza a la validez de la medida, pero más importante aún, la consecuencia es ética.

Esta propuesta sugiere diseñar un formulario con apropiadas instrucciones para capturar esta información, como la que se muestra en la Figura 1. De acuerdo a la experiencia anecdótica del investigador, el participante debe ser adecuadamente instruido para no hacer un traslape entre la experiencia de malestar relacionada con la situación descrita por el ítem, y el malestar producido al leer el ítem. En la primera, el contenido muestreado por el ítem naturalmente puede producir una respuesta emocional en el contexto inmediato de su aparición, y si el participante evalúa este vínculo, su juicio se dirigirá hacia un objetivo que no es consecuente con el objetivo de esta propuesta. Ambos son diferentes niveles de análisis, y el investigador debe asegurarse que el participante reconozca la diferencia.

La información obtenida mediante esta propuesta puede ser contrastada con la registrada por los jueces

\begin{tabular}{|c|c|c|c|c|}
\hline \multicolumn{4}{|c|}{} & $\begin{array}{c}\text { Impacto muy } \\
\text { fuerte }\end{array}$ \\
1 & 2 & 3 & 4 & 5 \\
\hline
\end{tabular}

Figura 1. Propuesta de exploración del impacto del ítem. Modelo de instrucciones. Le pedimos que, de acuerdo a su percepción, califique cada ítem/afirmación sobre el grado de impacto de cada ítem/afirmación que produciría al ser leído. El impacto se refiere a si el ítem puede producir alguna reacción emocional (como enojo, ansiedad o depresión, preocupación, etc.) y/o una sensación de incomodidad general. Por favor, tome en cuenta esto NO se refiere a la situación descrita por el ítem, sino a la reacción del encuestado al leer el ítem. Use una numeración del 1 (impacto trivial, realmente inofensivo) hasta 5 (impacto muy fuerte). 
expertos, y valorar ambas perspectivas. En la práctica de investigación, esta propuesta puede representar un mejor balance entre el rol activo del participante (históricamente llamado, sujeto de investigación), y la objetividad científica que se busca.

César Merino-Soto ${ }^{1}$ ${ }^{1}$ Universidad Autónoma del Estado de Morelos, Universidad de San Martín de Porres.

\section{Referencias}

1. Bromley E, Mikesell L, Jones F, Khodyakov D. From subject to participant: ethics and the evolving role of community in health research. American Journal of Public Health 2015; 105 (5): 900-8. https://doi.org/10.2105/ajph.2014.302403

2. Simon C, Mosavel M. Community members as recruiters of human subjects: ethical considerations. The American Journal of Bioethics 2010; 10 (3): 3-11. https://doi. org/10.1080/15265160903585578.

3. Teedon P, Galea KS, MacCalman L, Jones K, Cocker J, Cherrie JW, et al. Engaging with community researchers for exposure science: lessons learned from a pesticide biomonitoring study. PLoS ONE 2015; 10 (8): e0136347. https://doi. org/10.1371/journal.pone.0136347.
4. Paulhus DL, Vazire S. The self-report method. In: Robins RW, Fraley RC, Krueger RF, editors. Handbook of research methods in personality psychology. New York, NY, US: Guilford Press; 2007. p. 224-39.

5. Merino C, Livia C. Intervalos de confianza asimétricos para el índice la validez de contenido: Un programa Visual Basic para la V de Aiken. Anales en Psicología. 2009; 25 (1): 16971.

6. Merino-Soto C. Percepción de la claridad de los ítems: Comparación del juicio de estudiantes y jueces-expertos. Revista Latinoamericana de Ciencias Sociales, Niñez y Juventud. 2016; 14 (2): 1469-77. http://dx.doi.org/10.11600/169271 5x.14239120615.

Correspondencia a:

César Merino-Soto

Investigador en el Instituto de Investigación de Psicología

(Universidad de San Martín de Porres), y becario de la Universidad

Autónoma de la Universidad de Morelos (Centro de Investigación

Transdisciplinar en Psicología).

Calle Vieja 322, interior 116, Condominio Las Bugambilias 2 ,

CP: 62157, Colonia Lomas de Tzompantle, Cuernavaca, Morelos,

México.

sikayax@yahoo.com.ar

\section{Evolución del Juramento Hipocrático:} ¿qué ha cambiado y por qué?

\section{Evolution of the Hippocratic Oath: What has changed and why?}

\section{Señor Editor:}

El médico griego Hipócrates (aprox. 460 a.C.) es considerado el fundador de la Escuela Hipocrática en Cos, a la cual se le atribuye la creación del "juramento hipocrático"', que resume algunos principios éticos que guían al médico durante el ejercicio de su profesión. Dicho juramento ha sido actualizado en distintas ocasiones por la Asociación Médica Mundial (AMM), una organización internacional que busca representar a la profesión médica. En el presente artículo repasamos la historia de estas actualizaciones.
La primera actualización importante, conocida como "Declaración de Ginebra", se dio durante la segunda asamblea de la AMM en 1948, como reacción ante los crímenes médicos cometidos durante la segunda guerra mundial. Posteriormente, la Declaración de Ginebra fue enmendada en las Asambleas de la AMM en 1968, 1983 y 1994; y fue revisada editorialmente por el Consejo de la AMM en 2005 y en 2006. Finalmente, un grupo de trabajo ad hoc realizó modificaciones que fueron aprobadas por la Asamblea de la AMM en 2017, siendo ésta la versión actual del juramento hipocrático ${ }^{3}$, cuya versión en español está disponible en la página de la AMM: https://www.wma. net/es/policies-post/declaracion-de-ginebra. La comparación entre el juramento original, la Declaración de Ginebra de 1948 y la versión actual se muestra en la Tabla 1.

Algunos de los cambios más resaltantes que ha sufrido el juramento hipocrático son: 
Tabla 1. Modificaciones realizadas al juramento hipocrático

\section{Frase del juramento original}

Juro y pongo a Apolo el médico, y Asclepio e Hygiea y Panákeia y a todos los dioses y diosas como testigos, dar cumplimiento en la medida de mis fuerzas y de acuerdo con mi criterio a este juramento y compromiso

Haré uso del régimen dietético para ayuda del enfermo, según mi capacidad y recto entender: del daño y la injusticia le preservaré

No daré a nadie, aunque me lo pida, ningún fármaco letal, ni haré semejante sugerencia. Igualmente tampoco proporcionaré a mujer alguna un pesario abortivo. En pureza y santidad mantendré mi vida y mi arte

No haré uso del bisturí ni aun con los que sufren del mal de piedra: dejaré esa práctica a los que la realizan

Lo que en el tratamiento, o incluso fuera de él, viere u oyere en relación con la vida de los hombres, aquello que jamás deba trascender, lo callaré teniéndolo por secreto

A cualquier casa que entrare acudiré para asistencia del enfermo fuera de todo agravio intencionado o corrupción, en especial de prácticas sexuales con las personas, ya sean hombres o mujeres, esclavos o libres

Tener al que me enseñó este arte en igual estima que a mis progenitores, compartir con él mi hacienda y tomar a mi cargo sus necesidades si le hiciere falta; considerar a sus hijos como hermanos míos y enseñarles este arte, si es que tuvieran la necesidad de aprenderlo, de forma gratuita y sin contrato; hacerme cargo de la preceptiva, la instrucción oral y todas las demás enseñanzas de mis hijos, de los de mi maestro y de los discípulos que hayan suscrito el compromiso y estén sometidos por juramento a la ley médica, pero a nadie más

En consecuencia séame dado, si a este juramento fuera fiel y no lo quebrantare, el gozar de mi vida y de mi arte, siempre celebrado entre todos los hombres. Más si lo trasgredo y cometo perjurio, sea de esto lo contrario

\section{Frase final, como aparece en la Declaración de Ginebra actualizada de 2017}

Prometo solemnemente dedicar mi vida al servicio de la humanidad

Velar ante todo por la salud y el bienestar de mi paciente Respetar la autonomía y la dignidad de mi paciente Velar con el máximo respeto por la vida humana

No permitir que consideraciones de edad, enfermedad o incapacidad, credo, origen étnico, sexo, nacionalidad, afiliación política, raza, orientación sexual, clase social o cualquier otro factor se interpongan entre mis deberes $y$ mi paciente

Guardar y respetar los secretos confiados a mí, incluso después del fallecimiento del paciente

Ejercer mi profesión a conciencia y dignamente y conforme a la buena práctica médica

Promover el honor y las nobles tradiciones de la profesión médica

Otorgar a mis maestros, colegas y estudiantes el respeto y la gratitud que merecen

Compartir mis conocimientos médicos en beneficio del paciente y el avance de la salud

Cuidar mi propia salud, bienestar y capacidades para prestar atención médica del más alto nivel

No emplear mis conocimientos médicos para violar los derechos humanos y las libertades ciudadanas, incluso bajo amenaza

Hago estas promesas solemne y libremente, bajo mi palabra de honor 
1) La versión inicial del juramento fue acusada de promover una ética médica paternalista que centraba el tratamiento del paciente exclusivamente en la opinión del médico, lo cual podía prestarse como justificación a cometer atrocidades contra los pacientes. En los años 90 surge el principio ético de autonomía que surge en los años 90, por lo cual en la versión actual del juramento se agrega el "respetar la autonomía y la dignidad de mi paciente"s.

2) La versión inicial del juramento dejaba de lado asuntos importantes como las obligaciones del médico con las necesidades de la sociedad, por lo cual en la versión actual se agregó el "Compartir mis conocimientos médicos en beneficio del paciente y el avance de la salud"6.

3) Se consideró que, siendo una profesión de riesgo, la salud física y mental del médico debía ser óptima para poder brindar un adecuado cuidado a sus pacientes. Por ello, en la versión actual se agregó el "Cuidar mi propia salud, bienestar y capacidades para prestar atención médica del más alto nivel"4.

4) La versión inicial del juramento prohibía la realización de la eutanasia y el aborto. Sin embargo, al tener en cuenta el respeto por la autonomía de los pacientes, el respeto por los derechos reproductivos de las mujeres, y las complicaciones debido a la penalización del aborto; la versión actual del juramento solo menciona "Velar con el máximo respeto por la vida humana"7.

Si bien el juramento hipocrático es mundialmente conocido, es necesario que los médicos también conozcan sus actualizaciones, y puedan debatirlas y traducirlas a su práctica médica; en favor de un acto médico basado en lineamientos éticos adecuados a nuestros tiempos.

Jazmin M Sanchez-Salvatierra ${ }^{1,2}$, Alvaro Taype-Rondan ${ }^{3}$ ${ }^{1}$ Universidad Nacional Mayor de San Marcos, Lima, Perú.

${ }^{2}$ Sociedad Científica de San Fernando, Lima, Perú.

${ }^{3}$ Unidad de Investigación para la Generación y Sintesis de Evidencias en Salud, Universidad San Ignacio de Loyola, Lima, Perú.

\section{Referencias}

1. Remis J. Pasado y presente del juramento Hipocrático: Análisis de su vigencia. Rev Argent Radiol 2009; 73 (2): 139-41.

2. European Council of Medical Orders. Modern Physicians' pledge approved by World Medical Association [Internet]. 2017. Available from: http://www.ceom-ecmo.eu/en/modern-physicians-pledge-approved-world-medical-association-892.

3. Veatch RM. The Hippocratic ethic is dead. New Physician. 1984.

4. Askitopoulou H, Vgontzas AN. The relevance of the Hippocratic Oath to the ethical and moral values of contemporary medicine. Part I: The Hippocratic Oath from antiquity to modern times. Eur Spine J [Internet]. 2017; Available from: https://doi.org/10.1007/s00586-017-5348-4.

5. Asociación Médica Mundial. Declaración de Ginebra [Internet]. 2017. Available from: https://www.wma.net/es/ policies-post/declaracion-de-ginebra/

6. Federación Internacional de Ginecología y Obstetricia. Recomendaciones sobre temas de Ética en Obstetricia y Ginecología: Hecha por el Comité para el estudio de los aspectos éticos de la Reproducción Humana y Salud de la Mujer [Internet]. 2006. Available from: http://www2.congreso. gob.pe/sicr/cendocbib/con4_uibd.nsf/6289BABF568DC1E805257D160072C179/\$FILE/7_Guias_de_FIGO.pdf.

Conflictos de interés: Los autores declaran no tener conflictos de interés con respecto al presente artículo.

Financiamiento: El presente artículo fue autofinanciado por los autores.

Correspondencia a:

Jazmin M Sanchez-Salvatierra

Jr. Cailloma 437 dpto 402, Lima-Perú.

Teléfono: +51991010488

jazmin9394@gmail.com 